\title{
Oil sands pollutants in traditional foods
}

$\mathrm{O}$ il sands pollutants are making their way into First Nations' traditional food sources in northern Alberta, according to a new report, which also found a correlation between consumption of these foods and cancer rates in the Athabasca Chipewyan First Nation and the Mikisew Cree First Nation.

Research headed by Dr. Stéphane McLachlan, professor in the Department of Environment and Geography at the University of Manitoba in Winnipeg, found heavy metals and polycyclic aromatic hydrocarbons in higher than normal levels in First Nations' traditional food sources such as moose, duck and muskrat.

Levels of arsenic and mercury in muskrat, duck and moose were high enough to be of concern for children. Selenium levels were high enough in all wildlife species examined to be of concern for both children and adults.

The report also concluded that exposure to these contaminants was generally not in an amount to be of current health concern because of the low rate of traditional foods consumed among First Nations.

Still, the report suggests a correlation between the long-term exposure from eating traditional or "country" foods and cancer rates among the 113 people surveyed.

People who worked in the oil sands, as well as "people who consumed traditional foods more frequently and those who consumed locally caught foods were more likely to have cancer," said McLachlan in an interview.

Of the people surveyed, $21 \%$ had experienced cancer in some form.

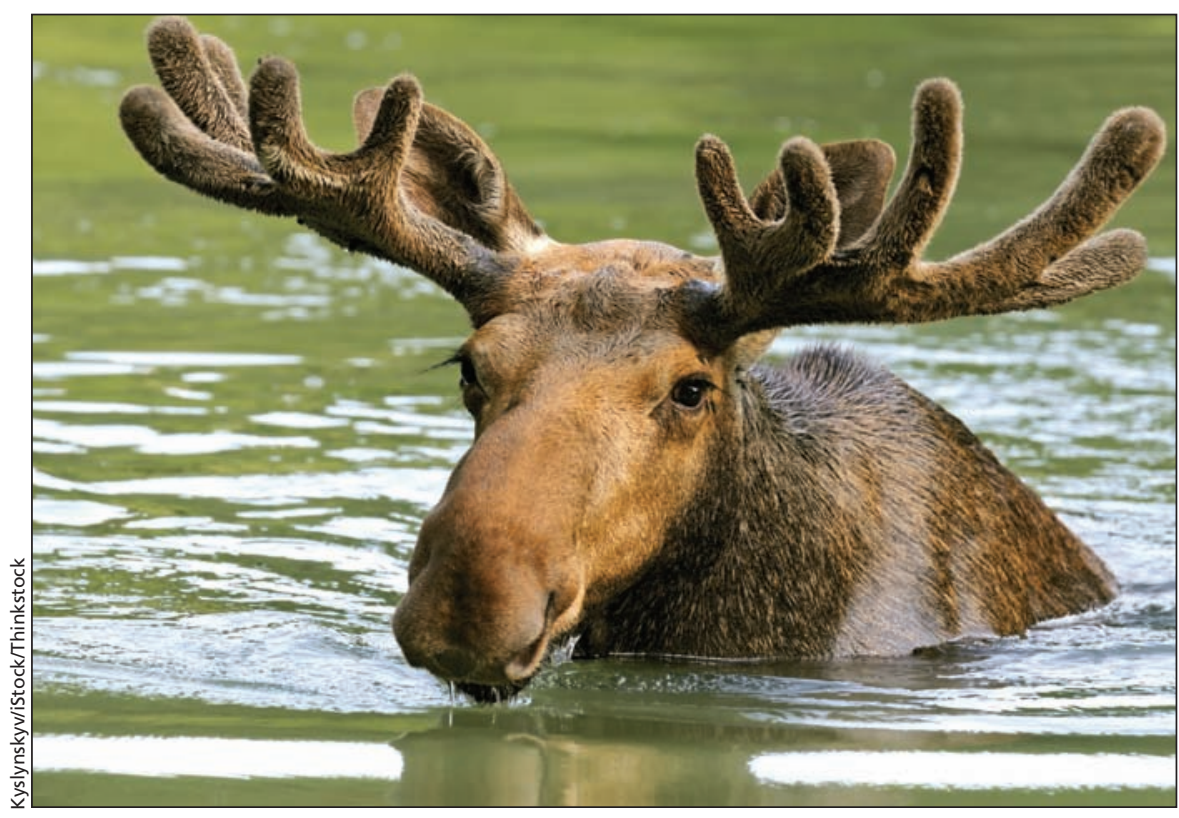

Levels of arsenic and mercury in muskrat, duck and moose were found in rates high enough to be of concern for children.

Concern about oil sands pollution is also driving the switch from traditional food sources to store-bought food, said the report.

"Industry is expediting that transition [to store-bought foods] in Fort Chipewyan because people are concerned about the quality of the traditional foods in a way that they wouldn't be in other parts of northern Canada," said McLachlan.

Meanwhile, the move away from traditional food is forcing First Nations into less healthy choices, because they encounter fewer options at the grocery store than most Canadians.

The products available in local stores are "convenience foods," said McLachlan. "The healthy foods that we like to promote in big cities like fresh fruits and vegetables just aren't available."

Funding for the report was provided by the Mikisew Cree First Nation, the Athabasca Chipewyan First Nation, Social Sciences and Humanities Research Council and Health Canada.

"We would like to see them start cleaning up and reducing the amount of effluent that is being put in the Athabasca River," said Chief Allan Adam of the Athabasca Chipewyan First Nation.

In October 2013, Alberta Health issued a consumption advisory for gull and tern eggs in the Lake Athabasca area after finding that they contained high levels of mercury. - Jocelyn Edwards, Calgary, Alta.

CMAJ 2014. DOI:10.1503/cmaj.109-4859 